\title{
Thyrotoxicosis, Etiology, Presentation and Management Challenges in Nigeria: A Review of Cases Seen Over a 5 Year Period
}

\author{
Belonwu Mends Onyenekwe, (MBBS, FMCP) \\ Department of Medicine, \\ University of Nigeria Teaching Hospital, Enugu, Nigeria
}

Doi:10.19044/esj.2019.v15n24p144 URL:http://dx.doi.org/10.19044/esj.2019.v15n24p144

\begin{abstract}
Background: Thyrotoxicosis is a common endocrine disorder worldwide with a female predominance. Graves disease is reported as the commonest cause of thyrotoxicosis by various authors in the Africa region. Aims and Objectives: The study evaluated patient characteristics, clinical and laboratory profile, co-morbidities, treatment modalities, response to therapy, side effects of anti-thyroid medications, treatment outcome and complications of the disease in patients with thyrotoxicosis. Materials and methods: This study was retrospective and observational. The records of patients diagnosed with overt thyrotoxicosis seen in the Endocrine unit (2013-2017) were pulled and relevant data compiled. Data was analyzed using SPSS V 21. Results: A total of 172 cases were studied; 33 males and 132 females (ratio 1:4). They were aged $18-70 ; 40.2 \pm 12.5$ years. Graves Disease constituted $79 \%$ of cases and toxic multinodular goiter made up $18 \%$. Seven cases of Marine Lenhart syndrome were identified. Graves orbitopathy occurred in 54\%, but was mild. All but 6 patients received anti-thyroid medication as initial therapy mainly carbimazole (90\%). About 6\% had thyroidectomy. Treatment default was high (52\%), while $15 \%$ remitted and $19 \%$ relapsed. Total duration of illness was 1$380,40.7 \pm 52.6$ months. Drug rash occurred in 5\% and cholestatic hepatitis in $1.8 \%$. Hypertension coexisted in $35 \%$. Six pregnancies were recorded, four of which ended in miscarriages, two of which had thyroid storm. Heart disease complicated the disease in $36 \%$. Conclusion: Thyrotoxicosis is a common clinical condition. Treatment with carbimazole is effective. However the treatment default rate was very high. Coexisting hypertension and pronlonged period of untreated disease exposed patients to a high burden of heart disease. Patient education and introduction of radioablation therapy will mitigate these challenges.
\end{abstract}


Keywords: Thyrotoxicosis, Presentation, Etiology, Treatment, Outcome, Complications, Heart disease

\section{Introduction}

Throtoxicosis is a common endocrine disorder worldwide. By definition, thyrotoxicosis refers to the clinical syndrome due to inappropriately raised circulating levels of thyroid hormones while hyperthyroidism implies increased synthesis and release of thyroid hormones by an overactive thyroid gland (Leo et al 2016). In general, the incidence of hyperthyroidism corresponds to population iodine nutrition. Various prevalence rates have been reported for hyperthyroidism in the general population in iodine sufficient areas of the world; $1-3 \%$ by Frankylen et al (2012) and $0.2 \%$ to $1.3 \%$ by Hollowell et al (2002). Higher rates of hyperthyroidism recorded in iodine deficient populations were ascribed to the excess of nodular thyroid disease in elderly patients (Laurberg et al 2006). Figures for the epidemiology of thyroid dysfunction in Africa are scarce due to absence of comprehensive populationbased studies (Taylor et al 2018). Long-term variations in iodine intake do not influence the risk of disease; however rapid repletion especially in regions of moderate-severe iodine deficiency increases the incidence of overt hyperthyroidism from toxic adenoma, toxic multinodular goiter, and Graves' disease (Laurberg 2006). This was the case following successful universal salt iodization (USI) programs in Congo, (Bourdoux 1996) Zimbabwe (Todd et al 1995) and Ghana (Sarfo-Kantanka et al 2017). Prior to 1993, Iodine Deficiency Disorders (IDD) was recognized as a public health problem in Nigeria. In 1994, the program of Universal Salt Iodization (USI) came into force and by 2005, Nigeria was certified as USI compliant (SCN News 2007). It is to be expected that the profile of thyroid diseases should shift from that of iodine deficient to iodine sufficient. Graves disease has been reported as the commonest cause of thyrotoxicosis by various authors in the Africa region (Sarfo-Kantanka et al 2017, Ogbera et al 2011).

\section{Aims and Objectives}

The study evaluated the demographic socioeconomic, clinical and laboratory profile and co-morbidities in patients with thyrotoxicosis attending our endocrine clinic. It also studied modalities of treatment, response to therapy and the side effects of anti-thyroid medications, treatment outcome and complications of the disease.

\section{Materials and methods}

This was a retrospective observational study. The records of patients diagnosed with overt thyrotoxicosis seen in the Endocrine unit of the 
University of Nigeria teaching Hospital (UNTH), Enugu, Nigeria over a 5 year period (2013-2017) were pulled and evaluated. Relevant data were compiled including patient demographics (age, gender, highest educational level attained, parity and occupation), presentation and clinical features, biochemical features (TSH, $\mathrm{fT}_{4}, \mathrm{fT}_{3}, \mathrm{TRAb}$ and TPO, FBC, serum urea and creatinine levels), treatment method, adverse drug reactions, duration of disease from inception, duration of treatment, disease status and treatment outcome. In addition, patients were assessed for co-morbidities and complications of therapy. Thyrotoxicosis was diagnosed based on suggestive clinical features in the presence of a suppressed TSH $(<0.01 \mu \mathrm{U} / \mathrm{mL})$ and elevated $\mathrm{fT}_{4}$. Thyroid autoantibodies were requested for confirmation of cases of autoimmunity due to Graves Disease. Thyroid profile and auto-antibody results prior to starting medical therapy were used for analysis. Treatment status on intake was classified as naïve (never received ATDs), previously treated (had received ATDs in the past) or ongoing (was on ATDs at intake). Biochemical severity of the thyrotoxicosis was assessed using free $\mathrm{fT}_{4}$ levels.

\section{Treatment method}

Only two methods of treatment were available; medical (ATD) and surgery (thyroidectomy). Carbimazole was the main and preferred ATD being the only drug readily available. All patients received carbimazole. Propylthioracil was used only in pregnancy or where carbimazole was not tolerated. The titration method was used starting with initial doses of 30$60 \mathrm{mg} /$ day and the dose tapered as the clinical features and biochemistry improved. Since 2015, the block and replace protocol was adopted to contain the arbitrary changes in ATD doses and chaotic thyroid function profile and therefore streamline the treatment algorithm. This problem arose because patients could not do their thyroid function tests as frequently and expeditiously as required. In this regime, Carbimazole was given at a steady dose of $30 \mathrm{mg}$ daily with 1-throxine $50-100 \mathrm{mg}$ daily added when $\mathrm{fT}_{4}$ level returned to normal (usually at 3 months). Treatment was discontinued after 18 months of ATD in those with controlled disease. They were then followed with thyroid function tests at one month and 3 monthly thereafter. The preferred beta blocker was propranolol which was used in all patients except where contraindicated. In such cases, atenolol was substituted. Patients who preferred surgery and those with nodular disease were referred to the surgical services. Surgery consisted of partial or total thyroidectomy.

\section{Treatment outcome}

The outcome of initial medical treatment was determined from biochemical response ( $\mathrm{fT}_{4}$ and $\left.\mathrm{TSH}\right)$ and clinical assessment and recorded as follows: 
1. Ongoing and controlled disease: normalization of biochemistry whilst on ATDs

2. Ongoing and uncontrolled disease: persistent symptoms or abnormal biochemistry despite ATDs

3. Disease remission: patients whose disease was controlled with ATDs and where control was maintained for at least a month after withdrawal of medical treatment or patients who remitted after thyroidectomy.

4. Defaulted: patients who did not complete the treatment schedule before discontinuing hospital attendance.

5. Relapsed: patients previously remitted or returned after defaulting

6. Unknown: where data or response were not available

Patients who relapsed after initial remission with ATDs or thyroidectomy were re-started on ATDs.

Data was analyzed using SPSS v 21 (SPSS, Inc, Chicago, IL, USA). Continuous variables were summarized using means and standard deviations. Categorical data was summarized using frequency tables and percentages. The relationship between variables was explored using $2 \times 2$ contingency tables to determine Chi squares and associated p-values. A $p$-value of $<0.05$ was considered statistically significant.

\section{Result}

\section{Demographics}

A total of 172 cases were studied; 33 males and 132 females (ratio 1:4). Table 1 and Figure 1 present the basic data on the patients. The ages of males and females were comparative $(p=0.332)$. Their diet consisted of local staples. Drinking water came from rivers, streams, boreholes, tap, sachet and bottled water. Family history of thyroid disease was present in $12 \%$, affecting primarily first degree relatives. All patients used iodized salt. None of the patients was on lithium or amiodarone. Alcohol and tobacco use was very insignificant.

Table 1, Patient demographics

\begin{tabular}{|c|c|c|}
\hline \multicolumn{3}{|l|}{ Total, 172} \\
\hline & \multicolumn{2}{|c|}{ Females, 132} \\
\hline Age (years) & \multicolumn{2}{|c|}{$18-70 ; 40 . .2 \pm 12.5$} \\
\hline & \multicolumn{2}{|c|}{$M=18-67 ; 41.6 \pm 14.2$} \\
\hline & \multicolumn{2}{|c|}{$\mathrm{F}=19-70 ; 39.9 .0 \pm 11.7$} \\
\hline Variable & $\mathrm{n}$ & $\%$ \\
\hline \multicolumn{3}{|c|}{ Education $n=137$} \\
\hline Primary & 22 & 20.5 \\
\hline Secondary & 38 & 38.5 \\
\hline Tertiary & 96 & 61.5 \\
\hline \multicolumn{3}{|c|}{ Marital status } \\
\hline Single & 54 & 31.4 \\
\hline
\end{tabular}




\begin{tabular}{|c|c|c|}
\hline Married & 111 & 64.5 \\
\hline Widowed & 7 & 4.0 \\
\hline \multicolumn{3}{|c|}{$0-10(4.0 \pm 2.5)$} \\
\hline \multicolumn{3}{|c|}{ Occupation } \\
\hline$\dagger$ Tech./Ass Prof & 26 & 15.1 \\
\hline † Cler/Supp Workers & 26 & 15.1 \\
\hline$\S$ Craft Rel/Trade Workers & 43 & 25.0 \\
\hline Students & 36 & 20.9 \\
\hline Others & 41 & 23.9 \\
\hline \multicolumn{3}{|c|}{ Family and social history } \\
\hline || Family hx goiter & 21 & 12.2 \\
\hline Family hx thyrotoxicosis & 2 & 1.2 \\
\hline Family hx vitiligo & 2 & 1.2 \\
\hline Use iodized salt & 169 & 98.3 \\
\hline Use extra iodized salt & 3 & 1.7 \\
\hline Herbals & 17 & 10.3 \\
\hline Supplements & 23 & 13.9 \\
\hline Contraceptive use & 1 & 0.6 \\
\hline Alcohol & 2 & 1.2 \\
\hline Tobacco & 2 & 1.2 \\
\hline
\end{tabular}

* Females only, $\uparrow$ Technical and Associate professionals, $\$$ Clerical and Support workers, $\S$ Craft Related and Trade workers, $\|$ hx-history

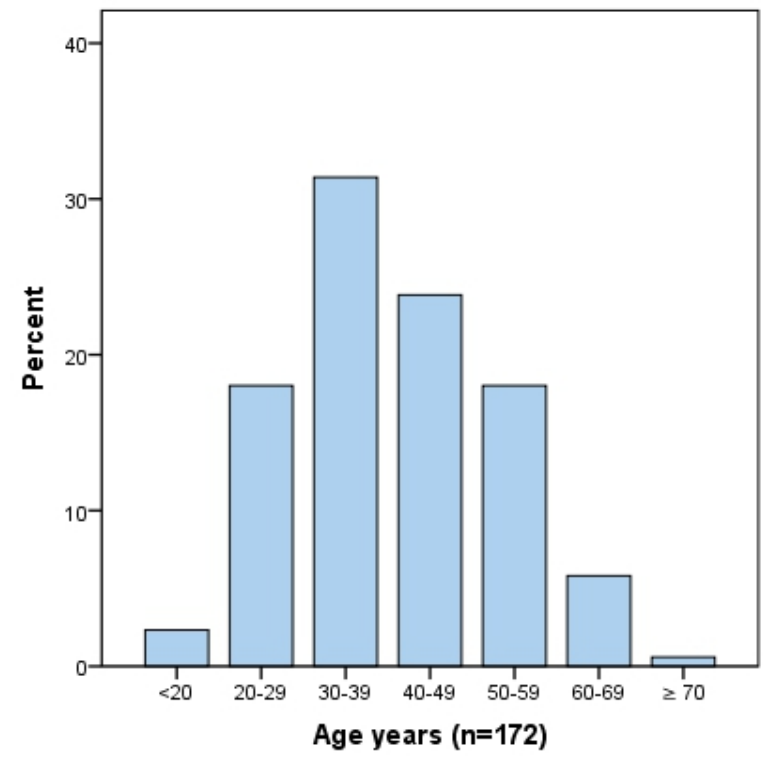

Figure 1, Age distribution of patients

\section{Clinical presentation}

The details of the presenting features are in Table 2 and 3 and Figure 2. The top ten symptoms were weight loss, heat intolerance, palpitations, hyper-defecation, excess sweating, goiter, increased appetite, bulging eyes, 
fatigue, and nervousness. The frequencies would have been higher if all patients were treatment naïve. The stool count was 2-20/day (5 53 , median 4). BMI could be assessed in only a third of the subjects where records were available. Tachycardia was recorded in $100 \%$ in all treatment naïve subjects. Of the ten subjects with irregularly, irregular pulse, one was male aged 49 years and the rest were female aged 35-68 years $(50.3 \pm 10.4$, median 51). Other common physical signs were goiter, eye signs, fine finger tremor, warm and moist palms. Pretibeal myxedema was observed in $4.1 \%$ and was of the diffuse and mixed (diffuse with nodules or plaque) types. No case of thyroid acropachy was recorded. Grade 0 goiters were observed in subjects on current or previous ATDs. Eye signs of Graves orbitopathy consisted of proptosis, periorbital edema and lid retraction. They were mild and regressed with ATD treatment except in two persons.

Table 2, Presenting symptoms

\begin{tabular}{|c|c|c|}
\hline Variable & $\mathrm{n}$ & $\%$ \\
\hline \multicolumn{3}{|c|}{ Treatment Status at intake } \\
\hline Naïve & 98 & 59.4 \\
\hline Current & 41 & 24.8 \\
\hline Previous & 26 & 15.8 \\
\hline \multicolumn{3}{|l|}{ Symptoms $(n=172)$} \\
\hline Weight loss & 148 & 86 \\
\hline Heat intolerance & 141 & 82 \\
\hline Palpitations & 140 & 81.4 \\
\hline Hyperdefecation & 128 & 74.4 \\
\hline Stool count & $2-20 ; 5 \pm 3$ & \\
\hline Appetite changes & 117 & 70.9 \\
\hline Same & 30 & 18.2 \\
\hline Increased & 101 & 61.2 \\
\hline Decreased & 16 & 9.7 \\
\hline Excess sweating & 116 & 67.4 \\
\hline Goiter & 109 & 63.4 \\
\hline Hand tremor & 107 & 62.2 \\
\hline Bulging eyes & 94 & 54.7 \\
\hline Grittiness eyes & $41^{\prime}$ & 23.8 \\
\hline Visual impairment & 10 & 5.8 \\
\hline Fatigue & 94 & 54.7 \\
\hline Nervousness & 89 & 51.7 \\
\hline Insomnia & 82 & 47.7 \\
\hline Shortness of breath & 73 & 42.4 \\
\hline * Menstrual changes $(n=132)$ & 62 & 47 \\
\hline Hypomenorrhea & 32 & 24 \\
\hline Amenorrhea & 24 & 18 \\
\hline Menorrhagia & 6 & 4.5 \\
\hline Postmenoupausal & 24 & 18 \\
\hline Leg swelling & 40 & 23.3 \\
\hline Muscle aches & 37 & 21.5 \\
\hline Polydipsia & 35 & 21.2 \\
\hline PMW & 32 & 18.6 \\
\hline
\end{tabular}




\begin{tabular}{|ccc|}
\hline Polyuria & 31 & 18 \\
\hline Cough & 28 & 16.3 \\
\hline Mood swings & 26 & 15.1 \\
\hline Orthopnea & 21 & 12.2 \\
\hline PND & 19 & 11.0 \\
\hline Skin hyperpigmentation & 20 & 11.6 \\
\hline Hair loss & 18 & 10.5 \\
\hline Pruritus & 14 & 8.1 \\
\hline Persistent headache & 11 & 6.4 \\
\hline Infertility & 10 & 5.8 \\
\hline Vitiligo & 4 & 2.3 \\
\hline Erectile dysfunction & 3 & 1.7 \\
Weight gain & 2 & 1.2 \\
Psychosis & 2 & 1.2 \\
Symptom duration before & $1-84 ; 18.6 \pm 18.5$, median 12 (months) \\
presentation & & \\
Females only & & \\
\hline
\end{tabular}

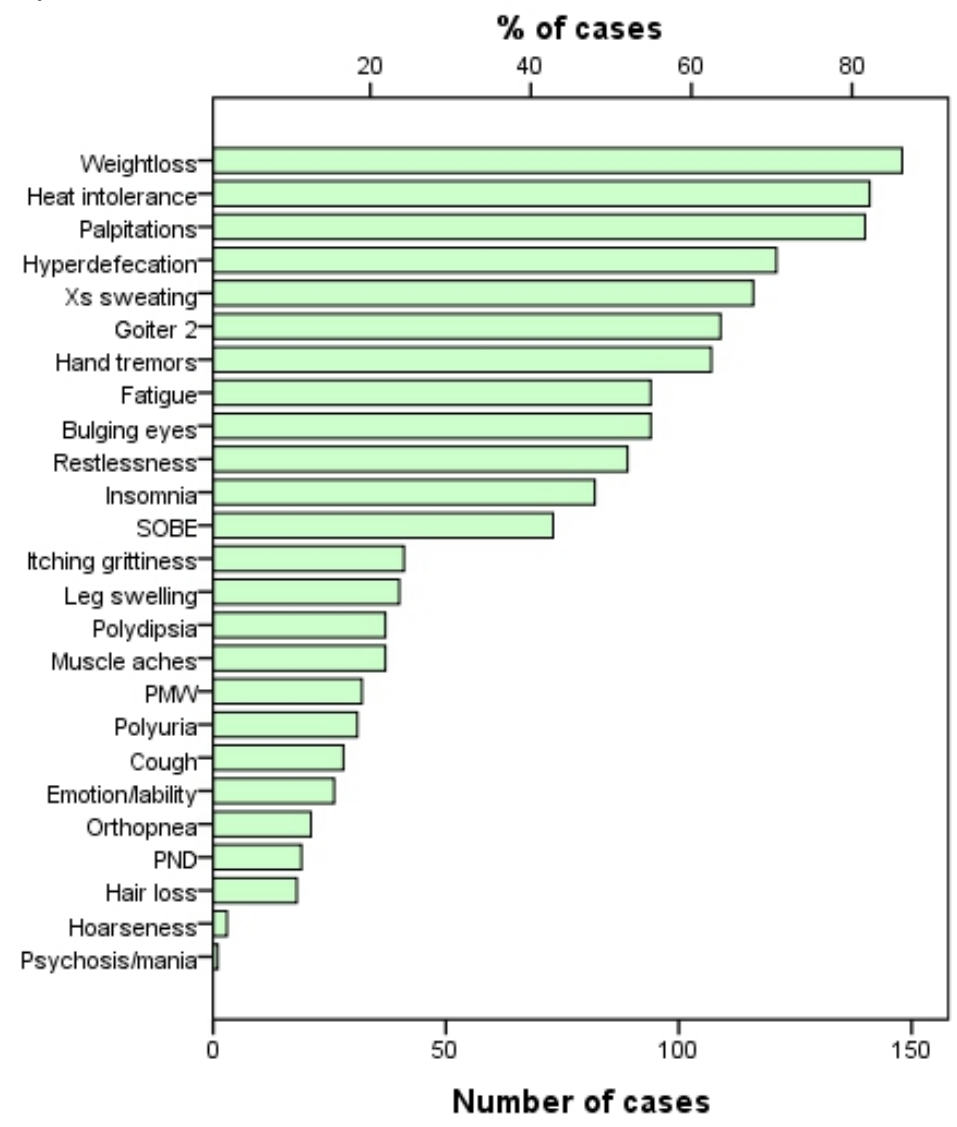

Figure 2, Frequency of symptoms 
Table 3, Physical and laboratory findings (n-172)

\begin{tabular}{|c|c|c|}
\hline Variable & $\mathrm{n}$ & $\%$ \\
\hline \multicolumn{3}{|l|}{ Appearance } \\
\hline Healthy calm & 99 & 60 \\
\hline Anxious & 47 & 28.5 \\
\hline Wasted & 39 & 23.6 \\
\hline Acutely ill & 4 & 2.4 \\
\hline Obese & 2 & 1.2 \\
\hline Apathetic & 2 & 1.2 \\
\hline BMI & \multicolumn{2}{|c|}{$15.6-33.2 ; 24.4 \pm 4.2$ median 23.9} \\
\hline Pulse rate & \multicolumn{2}{|c|}{$92-148 ; 113 \pm 12.7$, median 111} \\
\hline Irregular pulse & 10 & 6.9 \\
\hline Systolic blood pressure & \multicolumn{2}{|c|}{$80-190 ; 131 \pm 20$, median 130} \\
\hline Diastolic blood pressure & \multicolumn{2}{|c|}{$40-120 ; 77 \pm 13$, median 80} \\
\hline Goiter & 147 & 89.1 \\
\hline Grade 2 & 135 & 78.5 \\
\hline Grade 1 & 18 & 10.5 \\
\hline Grade 0 & 19 & 11 \\
\hline Diffuse & 127 & 73.8 \\
\hline Multinodular & 24 & 14 \\
\hline Single nodule & 2 & 1.2 \\
\hline Tender & 4 & 2.4 \\
\hline Eye signs & 102 & 59.3 \\
\hline Proptosis & 92 & 53.5 \\
\hline Symmetrical & 77 & 44.8 \\
\hline Asymmetrical & 11 & 6.4 \\
\hline Unilateral & 4 & 2.3 \\
\hline Chemosis & 2 & 1.2 \\
\hline Ophthalmoplegia & 4 & 2.3 \\
\hline Lid retraction & 95 & 55.2 \\
\hline Lid lag & 22 & 12.8 \\
\hline Sight loss & 1 & 0.6 \\
\hline Fine finger tremor & 95 & 55.2 \\
\hline Warm palms & 73 & 42.4 \\
\hline Moist palms & 38 & 22.1 \\
\hline Proximal myopathy & 18 & 10.9 \\
\hline Pedal edema & 17 & 10.3 \\
\hline Onycholysis & 13 & 7.6 \\
\hline Pretibial myxedema & 7 & 4.1 \\
\hline Vitiligo & 4 & 2.3 \\
\hline \multicolumn{3}{|l|}{ Illness Severity } \\
\hline Mild & 53 & 42.1 \\
\hline Moderate & 67 & 53.2 \\
\hline Severe & 6 & 3.5 \\
\hline \multicolumn{3}{|c|}{ Laboratory data } \\
\hline Hemoglobin & \multicolumn{2}{|c|}{$6.7-16.4 ; 11.9 \pm 1.6 \mathrm{~g} / \mathrm{dl}$} \\
\hline WBC & \multicolumn{2}{|c|}{$2.9-14 ; 5.7 \pm 1.8 \times 10^{9} / 1$} \\
\hline Urea & \multicolumn{2}{|c|}{$1.9-9.3 ; 4.1 \pm 1.5 \mathrm{mmol} / \mathrm{l}$} \\
\hline Creatinine & \multicolumn{2}{|c|}{$27-215 ; 967 \pm 27.5 \mu \mathrm{mol} / 1$} \\
\hline
\end{tabular}




\section{Etiologic Diagnosis}

The etiologic causes of the thyrotoxicosis are presented in Table 4. GD was diagnosed in $79 \%$, Toxic multinodular goiter (TMNG or Plummer's Disease) in $16.8 \%$ and Toxic adenoma (TA) in 1.8\%. There were single cases of thyroiditis and secondary hyperthyroidism (all females). There was no significant difference in the etiologic factors between males and females $(p=$ $0.910)$.

\begin{tabular}{|c|c|c|}
\hline \multicolumn{3}{|c|}{ Etiologic Diagnosis } \\
\hline Variable & $\mathrm{n}$ & $\%$ \\
\hline GD & 135 & 78.4 \\
\hline Males & 29 & 16.8 \\
\hline Females & 107 & 62.3 \\
\hline$\dagger$ MLS (females) & 7 & 4.0 \\
\hline TMNG & 31 & 17.6 \\
\hline Males & 5 & 2.9 \\
\hline Females & 26 & 15.1 \\
\hline Toxic Adenoma & 3 & 1.8 \\
\hline Male & 1 & 0.6 \\
\hline Female & 2 & 1.2 \\
\hline Thyroiditis & 1 & 0.6 \\
\hline 2 Hyperthyroidism & 1 & 0.6 \\
\hline \multicolumn{3}{|c|}{ Illness severity } \\
\hline Mild & 51 & 41.1 \\
\hline Moderate & 57 & 54.0 \\
\hline Severe & 6 & 3.5 \\
\hline
\end{tabular}

\section{Illness severity}

Illness severity was classified using $\mathrm{fT}_{4}$ cut off values according to Iglesias et al (2009) into Mild ( $\mathrm{fT}_{4} 1.8-3.9 \mathrm{ng} / \mathrm{dl}$ or 23-50 pmol/l); Moderate (3.8-50 ng/dl or 50-99 pmol/l) and Severe Hyperthyroidism (> $3.9 \mathrm{ng} / \mathrm{dl}$ or > $100 \mathrm{pmol} / \mathrm{l})$. This classification was only possible in subjects where $\mathrm{fT}_{4}$ was measured and this is shown in Table 4. Illness severity was comparative between males and females $(p=0.214)$.

\section{Thyroid auto-antibodies}

The level of thyroid autoantibody testing was very low, but has picked up in later years. Testing was selective targeting subjects with Graves Disease features and was possible only in those who could afford the test. TPO Ab were positive in all 34 (19.8\%) tested. (TRAb) in 32 (18.6\%) tested. Seven cases of Graves Disease with nodular goiter MLS were picked us a result of such testing; all females aged 33-56 (41.1 \pm 7.7$)$ years. 


\section{Treatment and medication adherence}

All subjects were offered ATD drugs except for 6 who defaulted before treatment could be started and the lone patient with thyroiditis (Table 5). In all, $163(90.1 \%)$ received ATDs only, while $10(6.1 \%)$ eventually underwent thyroidectomy. Carbimazole was commonly used (88.7\%). Treatment resulted in rapid regression of symptoms (4-12 weeks). The total treatment duration on ATDs was $1-65$ months $(16.0 \pm 15.2$, median 12 months $)$. Medication adherence was assessed as good in only $45 \%$. Some subjects used their medication intermittently and in $16 \%$, the status was unknown. The unknown cases were early defaulters where no meaningful assessment could be made. Adverse drug events with carbimazole resulted in pruritic, papular rash in $7.3 \%$ and hepatitis in $1.8 \%$. The hepatitis was cholestatic. The events occurred within 3-12 weeks of commencement of therapy (Table 5). The skin reactions were controlled with antihistamines and a short course steroid therapy in one case. The hepatitis resolved spontaneously on drug withdrawal.

Table 5, Disease management and outcome

Treatment

\begin{tabular}{|c|c|c|}
\hline Antithyroid medication & 164 & 95.3 \\
\hline Carbimazol & 154 & 89.5 \\
\hline Propylthiouracil & 10 & 5.8 \\
\hline Symptom free $(n=65)$ & \multicolumn{2}{|c|}{$4-12,8.1 \pm 3.0$, median 4 weeks } \\
\hline Treatment duration & \multicolumn{2}{|c|}{$1-65(16.0 \pm 15.2)$ months, Median 12 months } \\
\hline \multicolumn{3}{|l|}{ Medication adherence } \\
\hline Good & 77 & 44.8 \\
\hline Poor & 45 & 26.2 \\
\hline Intermittent & 27 & 15.7 \\
\hline Unknown & 27 & 16.4 \\
\hline \multicolumn{3}{|l|}{ Complication ATD } \\
\hline Rash & 9 & 5.2 \\
\hline Hepatitis & 2 & 1.2 \\
\hline Rash+hepatitis & 1 & 0.6 \\
\hline Latent period & \multicolumn{2}{|l|}{ 3-12 weeks } \\
\hline \multicolumn{3}{|l|}{ Final treatment modality } \\
\hline Medical & 156 & 90.1 \\
\hline Surgical & 10 & 5.8 \\
\hline No treatment & 6 & 3.5 \\
\hline \multicolumn{3}{|c|}{ Disease status at assessment } \\
\hline Controlled & 98 & 57 \\
\hline Uncontrolled & 68 & 39.5 \\
\hline No treatment & 6 & 3.5 \\
\hline \multicolumn{3}{|l|}{ Treatment status } \\
\hline Ongoing & 50 & 29.1 \\
\hline Defaulted & 89 & 51.7 \\
\hline Remitted & 26 & 15.1 \\
\hline No treatment & 6 & 3.5 \\
\hline Died & 1 & 0.6 \\
\hline Relapses & 24 & 14.0 \\
\hline
\end{tabular}




\begin{tabular}{llll} 
Post-carbimazole & \multicolumn{1}{c}{21} & 12.2 \\
Post-thyroidectomy & \multicolumn{2}{c}{3} & 1.7 \\
No of relapses & & & \\
1 & 14 & 8.1 & \\
2 & 8 & 4.7 & \\
3 & 2 & 1.2 & \\
Duration of illness & $1-380,40.7 \pm 52.6$ month &
\end{tabular}

\section{Disease and treatment status}

As at the time of assessment, the disease was controlled in 57\%, and uncontrolled in $39.5 \%$ of those treated (166). Of the 172 subjects, $52 \%$ had defaulted; treatment was ongoing in $29 \%$, while $15 \%$ met the criteria for remission (Table 5). Remissions occurred in 10 who underwent thyroidectomy and in 14 on ATDs. There were 24 relapses in the series ( 3 post-thyroidectomy and 21 post-carbimazole). The relapses occurred once in 14 persons (including all previous thyroidectomies), twice in eight persons and three times in two cases. Relapses here refer to subjects who returned with the illness after an initial treatment episode whether or not they met the criteria for remission in that episode.

\section{Co-existing conditions}

Hypertension was the commonest co-morbidity occurring in $35 \%$ of which 52\% had prior knowledge of this condition (Table 6). The hypertension was systolic (>140/<90 mm Hg) in only 12 of the $60(20 \%)$. Diabetes mellitus (DM) with or without hypertension was coexistent in 3.6\%. Others conditions are in listed in Table 6. The lone asthmatic patient was also hypertensive. Six pregnancies occurred during the illness.

\section{Thyrotoxicosis associated complications}

Thyrotoxicosis was associated with heart disease in $36 \%$ and overt heart failure in $9 \%$. Screening for heart disease was not routine; being undertaken in subjects who were hypertensive or had suggestive features of heart failure or were preparing for surgery. Diagnosis was based on presence of compatible signs on plain chest radiography, electrocardiography or $2 \mathrm{D}$ echocardiography (cardiomegaly, AF, left atrial abnormalities, LVH, systolic or diastolic dysfunction). The vast majority of GO was mild. Moderate-severe disease occurred in $2(1.2 \%)$. One was a lady aged 56 years with asymmetric disease, eye pain, chemosis and excess lacrimation. The other was a 64 years old man presenting solely with eye disease; proptosis, ophthalmoplegia, eye pain, chemosis, exposure keratitis, panophthalmitis and sight loss. These were the only ones requiring intervention. Two subjects came down with stroke and new onset Type 2 diabetes mellitus occurred in one subject. Of the 6 pregnancies that occurred during the illness, 4 ended in miscarriages and one 
in preterm delivery of a live baby. Thyroid storm occurred in $2(1.2 \%)$ of subjects who were pregnant. All the pregnant women unilaterally withdrew ATDs without physician knowledge fearing for the health of their baby. One death occurred in a subject whose disease was partially controlled, but died suddenly at home.

Co-existent conditions

Table 6, Co-morbidities and complications

\begin{tabular}{|ccc|}
\hline Hypertension & 60 & 34.9 \\
\hline HPN + DM & 3 & 1.7 \\
\hline DM & 3 & 1.7 \\
\hline PUD & 2 & 1.2 \\
\hline *DUB/Fibroids & 4 & 2.3 \\
\hline Bronchial Asthma & 1 & 0.6 \\
\hline Pregnancies & 6 & 3.5 \\
\hline †CKD & 1 & 0.6 \\
\hline Illness complications & & \\
\hline Heart Disease & 61 & 35.5 \\
\hline Overt heart failure & 15 & 8.7 \\
\hline Moderate-severe GO & 2 & 1.2 \\
\hline Thyroid storm & 2 & 1.2 \\
\hline Miscarriages & 4 & 2.4 \\
\hline Preterm delivery & 1 & 0.6 \\
\hline CVA & 2 & 1.2 \\
\hline DM & 1 & 0.6 \\
$*$ Dysfunctionsl uterine bleeding $\dagger$ chronic kidney disease
\end{tabular}

\section{Discussion}

\section{Presentation}

Thyrotoxicosis remains a disease affecting predominantly women. The age and gender distribution is similar to what is obtained in many developed countries which are iodine sufficient (Weetman 2000, Brent 2008). This is to be expected since population iodine nutrition in Nigeria has become optimal. The age distribution was unimodal.

The historical and examination findings are in keeping with the usual features of thyrotoxicosis found elsewhere; in the west, (Weetman 2000, Brent 2008, Smith et al 2016, DeGroot 2012), India, (Sahay 2011) Iran (Othman et al 2011) with local variations. Local researches have recorded similar findings including the series by Olurin as early as 1974 (Olurin 1974, Ogbera et al 2007, Sarfo-Kantanka et al 2018, Ayandipo et al 2018). Though 57\% of the patients had GO, only two required attention. Other authors reporting from the region had noted that the majority of patients with GO have mild ocular symptoms and require only minimal intervention. Chemosis, severe proptosis and ocular motility disorder were very rare. This has been related to the low prevalence of smoking in the disease population (Ogun et al 2016). The severity of thyroid eye disease has been linked to cigarette smoking (Åsvold 
et al 2007). Six variants of pretibial myxedema have been described; nodular, plaque, diffuse, tumor, mixed (combination of other variants) and elephantiasis types (Lan et al 2016). Two cases in this study were diffuse while the rest were of the mixed type. Vitiligo has a well known association with autoimmune diseases thyroid included and was present in 4 cases (Nunes et al 2011).

\section{Etiology}

Graves disease was the dominant cause of thyrotoxicosis in this report similar to other reports both local and global. It is possible that cases of thyroiditis with transient thyrotoxicosis may have resolved before patients could be referred to the Endocrine Clinic and therefore poorly represented in this report. One case of secondary hyperthyroidism due to thyrotrophin secreting pituitary adenoma was found and is awaiting surgery. Thyrotrophin secreting pituitary adenomas are notably rare (Beck-Peccoz 2000). The goiter in Graves disease is characteristically diffuse, but may not always be so. In the series by Bhargav (2014), the nature of the goiter can be nodular or atrophic. Goiter nodularity in Graves disease can also be due to simultaneous presence of toxic nodules; the Marine Lenhart Syndrome (Marine and Lenhart 1911, Charles 1973) Radioisotope scans may help in clarifying such cases. In this report, seven $(4.0 \%)$ of such cases of multinodular goiter by ultrasound with elevated TRAb titers and proptosis were identified.

\section{Treatment}

ATDs are preferred primary treatment for thyrotoxicosis in most countries other than North America. The initial dose of carbimazole is 15-30 $\mathrm{mg}$ daily for mild hyperthyroidism and $20-40 \mathrm{mg}$ daily for moderate to severe disease. Block and replace and titration regimens are equally effective (Abraham 2010). The block and replace regimen suited the local setting. ATD was very effective in controlling the disease as was documented in an earlier report from our center (Modebe 1992). The treatment default rate in this study was very high. This was also noted in the report by Olurin (1974) and Ogbera et al (2007). Adherence to long time therapies is problematic in this culture. Since ATDs were very effective, many patients considered themselves cured and left without reference to the physician. Work stoppages due to workers strike action are common in Nigeria and may last as long as four months; and occur at least once a year. During these periods, patients seek help elsewhere, usually private establishments and may never return. A number of the patients were students who returned to base or gained admission to universities and continued their treatment elsewhere. Similarly, patients requiring surgery may decide to do so in a private hospital of their choice and are lost to follow up. Moreover, there is no existing system for patient recall. All these factors have 
direct bearing on figures for treatment and disease outcome as outlined in the study. No categorical statement could be made about the remission rate under these circumstances which was only $15 \%$. An earlier study from the same center in the 1990s by Modebe (1992) yielded a remission rate of $61 \%$ on ATDs and a patient default rate of $32 \%$. Those with nodular goiter should proceed to surgery (total or near total thyroidectomy) as definitive treatment, but again quite a number could not be stabilized for surgery, cannot afford surgery or do not want surgery. Radioablation therapy would have been the most suitable alternative especially as the pharmaco-ecocomics is favorable (Ogunjobi et al 2015). However, both surgery and radioablation result in hypothyroidism requiring lifelong treatment with 1-thyroxine. This in itself presents another major problem. Again, hypothyroidism presents with nondescript signs and symptoms and more difficult to recognize than hyperthyroidism. For those with recurrent Graves Disease, some recent studies have reported that compared with radioactive iodine or thyroidectomy, a second course of ATD or prolonged low dose ATD treatment led to prolonged remission while minimizing the risk of side effects (Azizi et al 2005, Liu et al 2015, Villagelin et al 2015). Long-term continuous treatment of hyperthyroidism with methimazole is reported as safe (Hussain et al 2017). These treatment modalities are viable alternatives for such cases. Identification of patients at high risk for relapse (male sex, large goiters, a high $\mathrm{fT}_{3}$, low $\mathrm{TSH}$ levels, high TRAb and smoking) will assist in counseling patients on the best treatment approach (Hussain et al 2017, Liu et al 2017).

\section{Adverse drug reaction}

About 5\% of patients using ATDS will experience some drug related side effect most commonly a drug rash (Cooper 2005) Hepatotoxicity and agranulocytosis are uncommon. Cholestatic hepatitis occurred $1.8 \%$ of cases and resolved following drug withdrawal. Macula-papular rash and cholestatic hepatitis is typical of carbimazole induced drug reactions. No case of agranulocytosis was encountered.

\section{Thyrotoxicosis, hypertension and heart disease}

Thyroid hormones have profound effects on the heart and vascular system. $\mathrm{T}_{3}$ effect on heart function is mediated by genomic and non-genomic pathways (Biondi 2012). Thyrotoxicosis is characterized by an increase in resting heart rate, blood volume, stroke volume, myocardial contractility, and ejection fraction. Cardiac dysfunction is manifested by left ventricular hypertrophy, heart rhythm disturbances, heart chamber dilation and heart failure, pulmonary hypertension, systolic and diastolic dysfunction (Vargasuricoechea et al 2017). It is estimated that the prevalence of hypertension with thyrotoxicosis is 20-30\% (Prisant et al 2006). Thyrotoxicosis typically causes 
isolated systolic hypertension. However, in this study only in $20 \%$ of cases was the hypertension systolic suggesting pre-existing diastolic hypertension. The large burden of cardiac disease seen in thyrotoxicosis in Africa has been noted by several authors (Ogbera et al 2007, Anakwue et al 2015). This was attributed to some genetic susceptibility. However, analysis of present date as shown in Figures 3-5, demonstrate three factors to be highly contributory; namely coexistent hypertension $(p<0.001)$, duration of the disease $(p=0.039)$ and age of the patient $(p=0.020$. Older patients would have harbored the disease and hypertension for a longer period of time. Patients with partially or poorly treated thyrotoxicosis and hypertension, drift in and out of hospital for many years, in some cases for more than thirty years. Gender difference ( $p=$ $0.081)$ and etiologic diagnosis $(p=0.638)$ were not significant contributors. Patients with heart failure responded rapidly to ATD and anti-failure treatment.

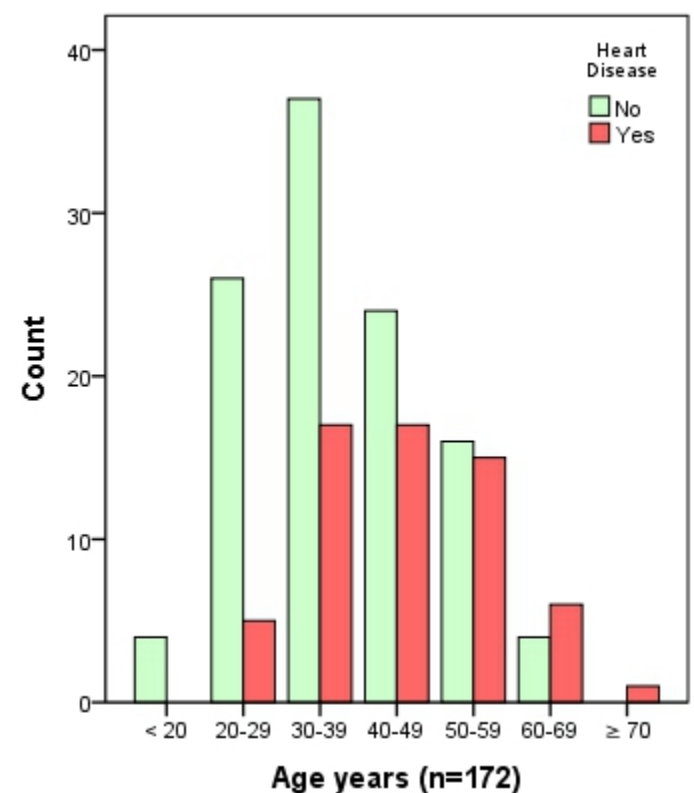

Figure 3, Heart disease and age of patients 


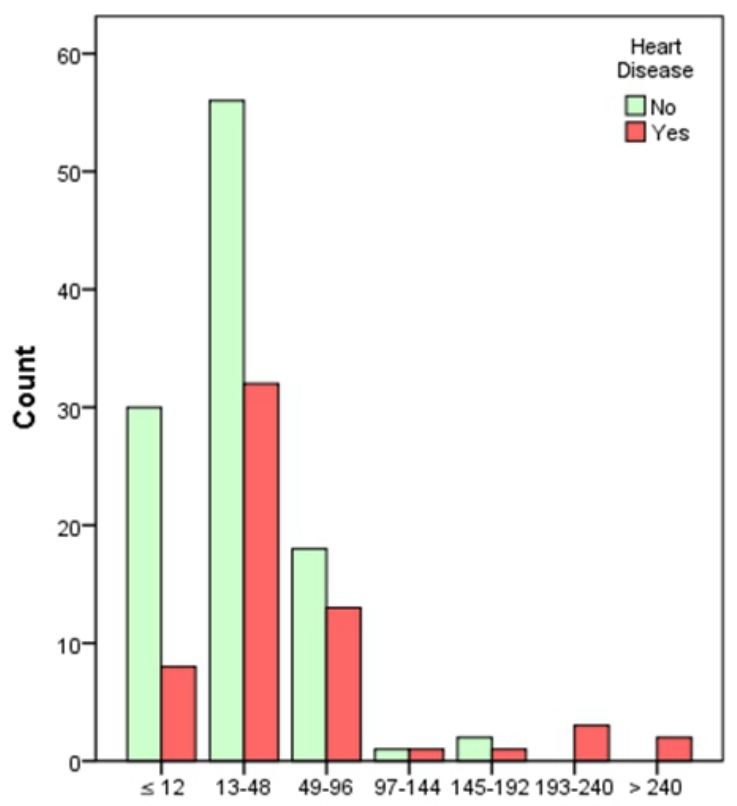

Total duration illness months $(\mathbf{n}=\mathbf{1 7 2})$

Figure 4, Heart disease and total duration of illness

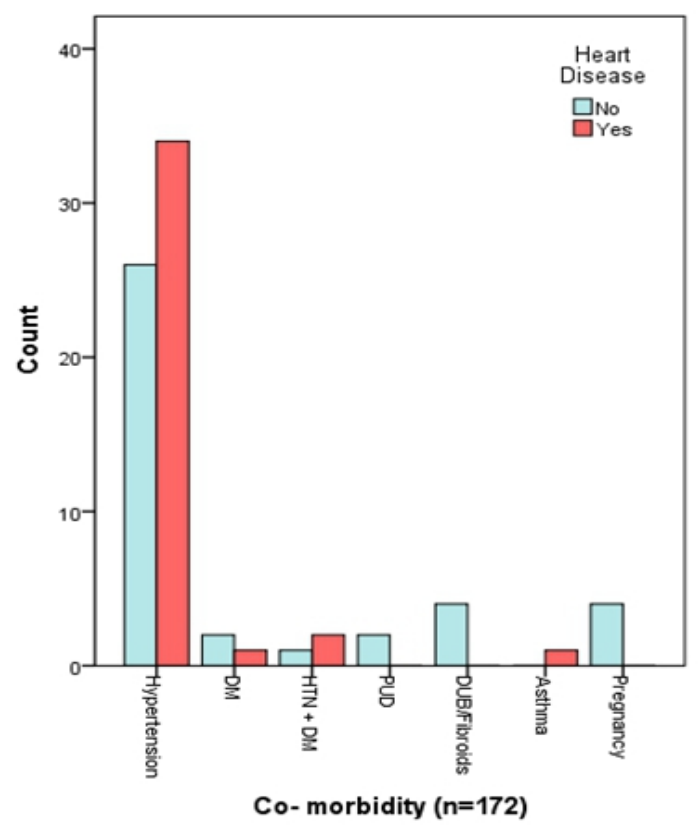

Figure 5, Heart disease and hypertension

\section{Conclusion}

Thyrotoxicosis is a common clinical condition. Treatment with carbimazole was effective but treatment outcome was marred by a high default 
rate. Coexisting hypertension and a prolonged period of untreated disease exposed patients to a high burden of heart disease. Patient education on the disease process, available treatment modalities and timeline and introduction of radioablation therapy will mitigate these deficiencies.

\section{Study limitation}

This study is limited by its retrospective nature and the lack of a complete dataset. Some of the folders could not be traced and in some folders, data was incomplete.

\section{Conflict of interest}

The author reports no conflict of interest.

\section{Funding}

The author received no funding for this researcht.

\section{References:}

1. Abraham, P., \& Acharya, S. (2010). Current and emerging treatment options for graves' hyperthyroidism. Therapeutics and Clinical Risk Management, $6(1)$, 29-40. https://doi.org/10.1016/j.annfar.2012.05.004

2. Anakwue, R. C., Onwubere, B. J., Ikeh, V., Anisiuba, B., Ike, S., \& Anakwue, A.-M. C. (2015). Echocardiographic assessment of left ventricular function in thyrotoxicosis and implications for the therapeutics of thyrotoxic cardiac disease. Therapeutics and Clinical Risk Management, 11, 189-200. https://doi.org/10.2147/TCRM.S68752

3. Åsvold, B. O., Bjøro, T., Nilsen, T. I. L., \& Vatten, L. J. (2007). Tobacco Smoking and Thyroid Function. Archives of Internal Medicine, 167(13), 1428. https://doi.org/10.1001/archinte.167.13.1428

4. Ayandipo, O. O., Orunmuyi, A. T., Akande, T. O., Ogun, OA, Afuwape, O. O., Afolabi, A. O, et al. 2018. "Presentation and Management Outcomes of Hyperthyroidism in a Sub -Saharan African Teaching Hospital." Annals of Thyroid Research, 4(1): 130-35.

5. Azizi, F., Ataie, L., Hedayati, M., Mehrabi, Y., \& Sheikholeslami, F. (2005). Effect of long-term continuous methimazole treatment of hyperthyroidism: Comparison with radioiodine. European Journal of Endocrinology, 152(5), 695-701. https://doi.org/10.1530/eje.1.01904

6. Beck-Peccoz, P., Persani, L., \& Lania, A. (2000). ThyrotropinSecreting Pituitary Adenomas. Endotext. MDText.com, Inc. Retrieved from http://www.ncbi.nlm.nih.gov/pubmed/25905212 
7. Bhargav, P. R. K. (2014). Heterogenous morphologic forms of goiter in autoimmune thyroid disease: An insight based on a prospective surgical series of 88 cases. World Journal of Endocrine Surgery, 6(2), 71-76. https://doi.org/10.5005/jp-journals-10002-1140

8. Biondi, B. (2012). Heart failure and thyroid dysfunction. European Journal of Endocrinology, 167(5), 609-618. https://doi.org/10.1530/EJE-12-0627

9. Bourdoux, P. P., Ermans, A. M., Mukalay wa Mukalay, A., Filetti, S., \& Vigneri, R. (1996). Iodine-induced thyrotoxicosis in Kivu, Zaire. Lancet (London, England), 347(9000), 552-3. https://doi.org/10.1016/S0140-6736(96)91188-5

10. Brent, G. A. (2008). Graves' Disease. New England Journal of Medicine, 358(24), 2594-2605. https://doi.org/10.1056/NEJMcp0801880

11. Charkes, N. D. (1973). Graves' disease with functioning nodules (Marine-Lenhart syndrome). J. Nucl. Med., 13 (12): 885-92.

12. Cooper, D. S. (2005). Antithyroid Drugs. New England Journal of Medicine, 352(9), 905-917. https://doi.org/10.1056/NEJMra042972

13. DeGroot, L. J. (2012). Graves 'Disease and the Manifestations of Thyrotoxicosis Thyroid

Disease

Manager.https:/www.thyroidmanager.org/chapter/graves-diseaseand-the manifestations-of-thyrotoxicosis/

14. Franklyn, J. A., \& Boelaert, K. (2012). Thyrotoxicosis. The Lancet, 379(9821), 1155-1166. https://doi.org/10.1016/S01406736(11)60782-4

15. Hollowell, J. G., Staehling, N. W., Flanders, W. D., Hannon, W. H., Gunter, E. W., Spencer, C. A., \& Braverman, L. E. (2002). Serum TSH, $\mathrm{T}_{4}$, and Thyroid Antibodies in the United States Population (1988 to 1994): National Health and Nutrition Examination Survey (NHANES III). The Journal of Clinical Endocrinology \& Metabolism, 87(2), 489-499. https://doi.org/10.1210/jcem.87.2.8182

16. Hussain, S. Z., Kumaran, M. P. (2017). Treatment for Graves’ Disease and its Recurrence. Journal of Medical Science And clinical Research, 5(7). http://jmscr.igmpublication.org/v5-i7/100\%20jmscr.pdf

17. Hussain, Y. S., Hookham, J. C., Allahabadia, A., \& Balasubramanian, S. P. (2017). Epidemiology, management and outcomes of Graves' disease-real life data. Endocrine, 56(3), 568-578. https://doi.org/10.1007/s12020-017-1306-5

18. Iglesias, P., Dévora, O., García, J., Tajada, P., \& Jj, D. (2009). HYPERTHYROIDISM. CLINICAL THYROIDOLOGY, 21(10), 79. 
19. Lan, C., Wang, Y., Zeng, X., Zhao, J., \& Zou, X. (2016). Morphological Diversity of Pretibial Myxedema and Its Mechanism of Evolving Process and Outcome: A Retrospective Study of 216 Cases. Journal of Thyroid Research, 2016, 2652174. https://doi.org/10.1155/2016/2652174

20. Laurberg, P., Jørgensen, T., Perrild, H., Ovesen, L., Knudsen, N., Pedersen, I. B., Vejbjerg, P. (2006). The Danish investigation on iodine intake and thyroid disease, DanThyr: status and perspectives. European Journal of Endocrinology, 155(2), 219-228. https://doi.org/10.1530/eje.1.02210

21. Leo, S. De, Lee, S. Y., Braverman, L. E., Unit, E., \& Sciences, C. (2016). HHS Public Access. Lancet, 388(10047), 906-918. https://doi.org/10.1016/S0140-6736(16)00278-6.Hyperthyroidism

22. Liu, J., Fu, J., Xu, Y., \& Wang, G. (2017). Antithyroid Drug Therapy for Graves' Disease and Implications for Recurrence. International Journal of Endocrinology, 2017. https://doi.org/10.1155/2017/3813540

23. Liu, X., Qiang, W., Liu, X., Liu, L., Liu, S., Gao, A., \& Shi, B. (2015). A second course of antithyroid drug therapy for recurrent Graves' disease: an experience in endocrine practice. European Journal of Endocrinology, 172(3), 321-6. https://doi.org/10.1530/EJE-14-0704

24. Marine, D., Lenhart, C. H. (1911). Pathological anatomy of exophthalmic goiter. Arch Intern Med., 8:265-316. http://archinte.jamanetwork.com/article. $\operatorname{aspx}$ ?articleid $=653460$

25. Modebe, O. (1992). Experience with carbimazole in the drug treatment of the hyperthyroidism of Graves' diseases in Nigerians. East African Medical Journal, 69(3), 153-6. http://www.ncbi.nlm.nih.gov/pubmed/1505405

26. Nations System Standing Committee on Nutrition, U. (2007). SCN News Vol 35 - Universal Salt Iodization (USI). http://189.28.128.100/dab/docs/portaldab/documentos/scnnews35.pdf

27. Nunes, D. H., \& Esser, L. M. H. (n.d.). Vitiligo epidemiological profile and the association with thyroid disease. Anais Brasileiros de Dermatologia, $\quad 86(2), \quad 241-8$. http://www.ncbi.nlm.nih.gov/pubmed/21603806

28. Ogbera, A. O., Fasanmade, O., \& Adediran, O. (2007). Pattern of thyroid disorders in the southwestern region of Nigeria. Ethnicity and Disease, 17(2), 327-330.

29. Ogbera, A. O., Fasanmade, O., \& Isiba, A. (2007). The scope of cardiac complications of thyrotoxicosis in Lagos, Nigeria. Pakistan Journal of Medical Sciences, 23(5), 671-675. 
30. Ogbera, A., \& Kuku, S. (2011). Epidemiology of thyroid diseases in Africa. Indian Journal of Endocrinology and Metabolism, 15(6), 82. https://doi.org/10.4103/2230-8210.83331

31. Ogun, O. A., \& Adeleye, J. O. (2016). Severe Ophthalmological Complications of Thyroid Disease are Rare in Ibadan, Southwestern Nigeria: Results of a Pilot Study. Ophthalmology and Eye Diseases, 2016(8), 5-9. https://doi.org/10.4137/OED.S32169.TYPE

32. Ogunjobi, K., Ejeh, J., Adedapo, A., \& Adedapo, K. (2015). Pharmacoeconomics of treatment options for hyperthyroidism: The Ibadan experience. Thyroid Research and Practice, 12(3), 100. https://doi.org/10.4103/0973-0354.159525

33. Okosieme, O. E. (2006). Impact of iodination on thyroid pathology in Africa. Journal of the Royal Society of Medicine, 99(8), 396-401. https://doi.org/10.1258/jrsm.99.8.396

34. Olurin, E. O. (1972). Thyrotoxicosis in Nigeria-a study of forty-six patients. Postgraduate Medical Journal, 48(564), 609-615. https://doi.org/10.1136/pgmj.48.564.609

35. Othman, T., \& Mahwi, A. (2011). Thyrotoxicosis-10 Years Experience, 10(2), 170-179.

36. Prisant, L. M., Gujral, J. S., \& Mulloy, A. L. (2006). Hyperthyroidism: a secondary cause of isolated systolic hypertension. Journal of Clinical Hypertension (Greenwich, Conn.), 8(8), 596-599. https://doi.org/10.1111/j.1524-6175.2006.05180.x

37. Sarfo-Kantanka, O., Kyei, I., Sarfo, F. S., \& Ansah, E. O. (2017). Thyroid Disorders in Central Ghana: The Influence of 20 Years of Iodization. Journal of Thyroid Research, 2017, 1-7. https://doi.org/10.1155/2017/7843972

38. Sarfo-Kantanka, O., Sarfo, F. S., Ansah, E. O., \& Kyei, I. (2018). Graves Disease in Central Ghana: Clinical Characteristics and Associated Factors. Clinical Medicine Insights: Endocrinology and Diabetes, 11. https://doi.org/10.1177/1179551418759076

39. Smith, T. J., \& Hegedüs, L. (2016). Graves' Disease. New England Journal of $\quad$ Medicine, 1575(16), https://doi.org/10.1056/NEJMra1510030

40. Taylor, P. N., Albrecht, D., Scholz, A., Gutierrez-Buey, G., Lazarus, J. H., Dayan, C. M., \& Okosieme, O. E. (2018). Global epidemiology of hyperthyroidism and hypothyroidism. Nature Reviews Endocrinology, 14(5), 301-316. https://doi.org/10.1038/nrendo.2018.18

41. Todd, C. H., Allain, T., Gomo, Z. A., Hasler, J. A., Ndiweni, M., \& Oken, E. (1995). Increase in thyrotoxicosis associated with iodine supplements in Zimbabwe. Lancet (London, England), 346(8989), 
$1563-4$.

Retrieved

from

http://www.ncbi.nlm.nih.gov/pubmed/7491075

42. Vargas-Uricoechea, H., Bonelo-Perdomo, A., \& Sierra-Torres, C. H. (2014). Effects of thyroid hormones on the heart. Clínica e Investigación En Arteriosclerosis, 26(6), 296-309. https://doi.org/10.1016/j.arteri.2014.07.003

43. Villagelin, D., Romaldini, J. H., Santos, R. B., Milkos, A. B. B. P., \& Ward, L. S. (2015). Outcomes in Relapsed Graves' Disease Patients Following Radioiodine or Prolonged Low Dose of Methimazole Treatment. Thyroid, $25(12)$ 1282-1290. https://doi.org/10.1089/thy.2015.0195

44. Weetman, A. P. (2000). Graves' Disease. New England Journal of Medicine, 343(17), $1236-1248$. https://doi.org/10.1056/NEJM200010263431707 